\title{
Innovations
}

\section{"Sparkling Moments": Graphic medicine as a reflective tool for self-efficacy and motivation}

\author{
Medical Humanities in the Middle East Conference \\ November 17-18, 2018 \\ Doha, Qatar
}

\section{Authors}

Linda Miller ${ }^{*}$

\section{Abstract}

Physician Health and Well-being is a significant issue globally. Doctors suffer from more depression, dependence, divorce and suicide than other professions. Burn out is a common problem; several studies have found it to affect more than half of doctors questioned. In order to provide compassionate care, care givers need to be treated with compassion. Reflection is demanded by governance processes-training, assessment, appraisal and Revalidation-but generally reflection is on negative outcomes in healthcare and "significant events". Medical culture has a strong negativity bias.

An innovative, interactive workshop was developed using a methodology unique in combining "Arts in Health", creative methods, and the Medical
Humanities, with a supervised, reflective practice. The "Sparkling Moments" exercise was initially developed by Psychotherapist and supervisor Robin Shohet and Leadership Coach, Eric De Haan; "Sparkling Moments" as a written exercise encourages reflection on positive aspects of work.

Relevant in any work context, the cartooning process has proved popular with those working in the caring professions: health and social care, medical education, coaching and mentoring and supervision. It has been successful Internationally including a conference in Istanbul (The World conference for Family Doctors; WONCA, 2015). The session includes an introduction by the two presenters about the Medical Humanities and the evolution of cartoons and graphic medicine as a serious genre of narrative and pathography (patients' stories about illness).

Examples shared introduce graphic methods such as the use of colour, size, text, panels and "gutters"
'NHS, London, UK

*Email: lindamiller@doctors.org.uk

Linda Miller iD https://orcid.org/0000-0002-0495-3832

\section{Cite this article as:}

Miller L. "Sparkling Moments": Graphic medicine as a reflective tool for self-efficacy and motivation. In: Weber AS, Verjee MA, editors. Proceedings of the lst International Conference on Medical Humanities in the Middle East [Internet]; $2018 \mathrm{Nov}$ 17-18: Doha, Qatar: Innovations in Global Health Professions Education; 2019 March. p. 54-55. (Innovations in Global Health Professions Education; vol. 2019, spec. no.: 1). https://dx.doi. org/10.20421/ighpe2019.01.19

This is an open access article distributed under the terms of the Creative Commons Attribution license CC BY 4.0, which permits unrestricted use, distribution and reproduction in any medium, provided the original work is properly cited. 
between panels. After some examples from graphic novels and previous workshop participants' "Sparkling Moments", the participants are invited to reflect on a "Sparkling Moment" in their own practice. The workshop participants draw their own "Sparkling Moment cartoon", before sharing stories in small groups. A structured appreciative enquiry process is used for group members to offer positive feedback about the behaviours described in each graphic narrative. The story teller receives appreciative feedback from peers who understand the challenges of their work setting; they recall a positive experience and gain affirmation that they are doing a good job and having an impact. Research shows that the most important element of job satisfaction is the feeling of doing meaningful work which is valued.

A plenary allows participants to consider the added insights they have gained from the process of drawing their story and presenting their narrative in a visual form and from receiving peer appreciative feedback. This methodology utilises positive psychology to enhance self-efficacy, sense of community and motivation. These aspects of engagement and countering burnout are often neglected by traditional "resilience" promotion activities.

Themes identified from a series of workshops with clinicians from a range of specialities and grades in the UK, Turkey, Paris and USA are summarised. The findings confirm that motivation in healthcare work has nothing to do with financial gain but is related to self-efficacy: doing work which is meaningful, valued and appreciated.
Conflicts of interest: None.

Funding sources: None.

\section{About the author}

Dr. Linda Miller, FRCGP, has been a London General Practitioner for 21 years and is a Fellow of the RCGP. She has coached doctors and dentists since training as a coach in 2008 with the London Deanery. She has the Institute of Leadership and Management Diploma in Coaching. Dr. Miller has been involved in the training assessment, supervision and appraisal of many coaches. She has the Diploma in Coaching Supervision from the Coach Supervision Academy. She has published articles about Coaching and Mentoring and presented at International Conferences. An experienced Medical Educator, she is a GP Appraiser and teaches Communication Skills, Resilience, Medical Humanities and Medical Ethics at Imperial College, London. Having completed an MSc in Medical Humanities at King's College London in 2015, she incorporates Medical Humanities into her portfolio of work in Medical Education and Physician Well Being. She is commencing a Medical Humanities PhD at Birkbeck, University of London. 